\title{
LICHEN PLANUS COEXISTING WITH DIABETES MELLITUS AND HYPERTENSION (GRINSPAN'S SYNDROME) - DESCRIPTION OF TWO CASES
}

\author{
Kamila Grabowska-Szeląg', Izabella Tomera-Niekowal', Barbara Kęsek² \\ ${ }^{1}$ Centre of Periodontal Diseases and Oral Mucosa, Consultation Conservative Dentistry Clinic, Zbigniew Żak Regional Dental Clinic in Krakow, Poland \\ ${ }^{2}$ Department and Faculty of Periodontology and Clinical Pathologies of Oral Cavity, University Dental Clinic in Kraków, Poland
}

\begin{abstract}
INTRODUCTION: Lichen planus is a chronic skin and oral mucosa disease. Coexistence of the oral form of lichen planus with diabetes and hypertension was described for the first time by Grinspan in 1963.

CASE DeSCRiption: Two cases of the occurrence of lichen planus in patients with diagnosed diabetes and hypertension (Grinspan's syndrome) are presented. In the first case, diabetes and hypertension treatment were accompanied by lesions in the oral cavity and on the skin of shins. In the other case, lichen planus type lesions were manifested only in the oral cavity.

ConcLusions: The aetiology of lichen planus remains unclear to some extent. Detailed diagnostics is based on clinical examination, general medical history and histopathological findings. The risk of malignant transformation of oral lichen planus ranges from 0.4 to $5.3 \%$ and it regards mainly the erosive form. Regular follow-up visits and oncological vigilance constitute an inseparable part of treatment.
\end{abstract}

KEY wORDs: oral lichen planus, diabetes, hypertension, Grinspan’s syndrome.

J Stoma 2018; 71, 5: 449-456

DOI: https://doi.org/10.5114/jos.2018.84648

\section{INTRODUCTION}

Lichen planus (LP) is a chronic inflammatory autoimmune disease of skin and oral mucosa, which affects stratified squamous epithelium of the skin and oral mucosa. It may progress with exacerbations and remission periods [1-3].

It is a relatively frequent disease affecting $0.1-2.0 \%$ of the population [4], occurring in people aged 30 to 70 . In about $60 \%$ of cases it affects women [5], although some authors indicate higher male predilection $[6,7]$. It is spread globally and it may vary depending on race and geography $[4,7]$.
The causes and pathogenesis of LP remain unclear, but some evidence shows that it is an immunological disorder, in which $\mathrm{T}$ lymphocytes show activity towards the epithelial antigen [8]. Such reaction is histologically proximate to the immune response of a chronic graftversus-host disease (cGVHD) [8, 9]. The histopathological evaluation of early lesions of oral LP indicates the prevalence of $\mathrm{T}$ helper lymphocytes (CD4+), whereas in advanced forms T cytotoxic lymphocytes (CD8+) are prevalent [10]. Other likely etiological factors include infection (virus, including HCV, ca. 5.4\%), metabolic (vitamin deficiencies), genetic and psycho-neurogenic factors [10-14].

\section{JOURNAL OF} STOMATOLOGY CZASOPISMO STOMATOLOGICZNE

ADDRESS FOR CORRESPONDENCE: lek. stom. Izabella Tomera-Niekowal, Zbigniew Żak Regional Dental Clinic in Krakow, 3 Batorego St., 31-135 Kraków, Poland, phone: +48 1263376 18, e-mail: i.tomera@interia.pl 
Lesions may involve skin and mucous membranes. According to Jańczuk, lesions involve the oral cavity in $50 \%$ of people with skin lesions. There are also cases of lesions occurring on the genital mucosa $[3,15,16]$. Isolated oral lichen planus (OLP) can be observed in $13-53 \%$ of cases. The most frequent location of lesions in the oral cavity is cheeks, tongue, lips and gums. Also characteristic is the usually symmetric and bilateral location of such lesions [3, 17].

The clinical picture of OLP varies. The basic lesion is a papule, yet intraoral lesions may range from white, tree-shaped, asymptomatic forms, to painful erosions and ulcerations surrounded by papules [18]. Andreasen distinguished 6 forms: follicular, reticular, plaque-like, atrophic, erosive and bullous. This classification has been accepted by the WHO. A follicular, reticular and plaque-like form is referred to as the "white lichen planus", whereas an erosive, atrophic and bullous form is referred to as the "red lichen planus". The most frequent is the reticular form with numerous overlapping keratotic lines or stripes, the so-called Wickham striae. Knychalska-Karwan differentiates between a simple and a complex form, whereas Jańczuk enumerates tree-shaped, circinate (lichen annularis), atrophic (lichen atrophicus), hypertrophic (lichen hypertrophicus), confluencing (lichen confluens), and bullous (lichen pemphigoides) forms [3, 5, 19-21].

In clinical practice, one may use a simplified version of OLP classification proposed by Bagan-Sebastian, indicating two forms: reticular - R (only with the presence of white striae or papules) and more advanced atrophic - erosive-AE (with erosions and blisters) [21, 22].

Lesions in alveolar gingiva in the course of OLP indicate the presence of desquamative gingivitis, which is observed in $25 \%$ of cases and most frequently it concerns women (72.9\%) [23]. A characteristic symptom of active forms of the disease is the so-called Köbner's phenomenon, which is a response to mechanical irritation. Clinical manifestation of the Koebner response is the occurrence of some reaction in the form of papules in the place of a mechanical stimulus within 7-14 days $[24,25]$.

Skin lesions in the course of LP accompany symptoms in the oral cavity in $30 \%$ of patients. Predilection to the occurrence of lesions is indicated by the internal surface of wrists, thighs, the lumbar region and the front shin surface, and similarly to the oral form, lesions frequently occur symmetrically. They may have the form of itching reddish papules, $3-4 \mathrm{~mm}$ in diameter, and with time they increase, amalgamate and change colour to bluish-purple, violet or brown $[3,5,24]$.

Diagnostic difficulties with unambiguous characterisation of the OLP pattern may be caused by lesions which clinically can suggest LP. These are the so-called oral lichenoid lesions (OLL), described for the first time by Almeyda \& Levantine in 1971 [26]. There are certain clinical and histological features which make it possible to dis- tinguish a lichenoid reaction from classical LP. Lichenoid lesions are distinguished by a tendency to occur unilaterally and their development, contrary to the idiopathic OLP background, is closely related to the activity of wellknown chemical compounds, such as mercury (present in amalgam fillings), gold, composite materials or acryl. It is interesting that lichenoid lesions can be induced by systemic pharmacotherapy, with a particular emphasis on non-steroidal anti-inflammatory drugs (NSAID), angiotensin drugs, beta blockers, cardiac glycosides, antimalarial drugs, sulfasalazine, sulphonylurea components, diuretics, as well as antidiabetic drugs [26-31]. Remission of lesions within 2-3 months after removing a causal factor or after discontinuation of drugs suggests the clinical diagnosis of a lichenoid lesion [32]. A decisive test, enabling final diagnosis, is histopathological verification. In the histopathological picture, in the case of LP, a characteristic shape of epithelium structures looking like "saw tooth" is identified. Hyper- and parakeratosis, keratinocyte degeneration of the epithelium basal layer, damage of elastic and collagen fibres, as well as inflammatory cells (lymphocytes, histiocytes and mast cells) are observed concurrently [32-35]. An immunofluorescence test may turn out helpful in distinguishing between OLP and OLL. Direct immunofluorescence shows linear concentration of IgM, IgA deposits and complement component C3, along the basal membrane in the case of both OLP and lichenoid lesions [36]. In indirect immunofluorescence in the case of drug-induced lesions, a picture of antibodies arranged like a "string of pearls" is characteristic [30-32] (Table 1).

Grinspan's syndrome is characterised by the occurrence of a triad of symptoms: LP, diabetes and hypertension. This syndrome was observed by Grinspan and his associates, who presented coincidence of the erosive LP with hypertension and diabetes, and the results of their studies were announced at the Dermatology Congress in Buenos Aires in 1963. Grupper and Avul's studies seemed to confirm the existence of that symptomatologic triad, called by the authors "Grinspan's syndrome" [37]. Other

TABLE 1. Modified World Health Organization criteria for the diagnosis of oral lichenoid lesions and oral lichen planus (according to [6])

\section{Clinical criteria}

- Bilateral occurrence of more or less symmetrical pathological lesions

- Presence of white striae (or reticulum pattern)

- Erosive, atrophic, bullous and plaque-like forms are considered subtypes when they accompany the reticulum occurrence in other areas of mucosa

Histological criteria

- Infiltration consisting of lymphocytes in the surface layer of connective tissue

- Signs of degeneration in the base layer of epithelium

- No epithelial dysplasia 
authors link more frequent occurrence of LP lesions in patients with hypertension or diabetes to the drugs used by them. In this situation, Lamey and associates suggested that Grinspan's syndrome may be iatrogenically induced, whereas lesions in the oral cavity are only a lichenoid reaction in response to systemic treatment $[3,32]$. The proper mechanism of drug-induced OLP pathogenesis remains unclear. One of theories indicates damage of keratinocytes of the epithelium basal layer with antibody creation [38]. A certain link is also suggested between endocrinological disorders in the course of diabetes and the occurrence of immunological defects contributing to OLP development [39].

The goal of this study was to present a treatment protocol and results of patients with OLP lesions, who underwent systemic treatment in the course of diagnosed diabetes and hypertension (Grinspan's syndrome).

\section{CASE DESCRIPTION}

\section{CASE 1}

Patient A.D., 68 years old, was referred by a dental prosthetics specialist in order to diagnose and treat lesions on the oral mucosa. Lesions were discovered during routine dental examination before the planned prosthetic treatment. Reported disorders included the sense of dryness of the mouth and periodic discomfort in the buccal mucosa, particularly intense when eating sour and spicy food.

A general medical history provided information about coexisting general diseases, namely hypertension diagnosed in 1992 (treated with Betaloc ZOK 100 mg: 1-0-0, Tritace $2.5 \mathrm{mg}$ : 0.5-0-0) and type 2 diabetes diagnosed in 1993 (Siofor 850 mg: 0-0-2, Glibetic 3 mg: 1-0-0).

Additionally, the interview provided information about myocardial infarction suffered in 2007 and about permanent dermatological treatment of a skin form of LP with Lorinden (3 times a day). Dermatological treatment had been conducted for about 3 years. The patient mentioned itching of skin lesions and the occurrence of new lesions in the place of irritation. The patient did not smoke and consumed alcohol only occasionally.

Extraoral clinical examination of the face skin did not show any lesions. Lymph nodes were not painful and were undetectable in palpation. On the skin of the left shin purplish red papules of different sizes $(2-30 \mathrm{~mm})$ were reported, with a shiny surface, with poorly marked small white lines, the so-called Wickham striae (Figures 1 and 2).

In the intraoral clinical examination, interdental gaps were found in the maxilla and the mandible: class IV according to the Galasińska-Landsberger classification. In Eichner's classification: B3. For about 7 years, the patient had used a partial upper acrylic prosthesis and a partial lower prosthesis. In the area of prosthetic restorations they were found not sufficiently in contact with the prosthetic base. The hygiene of the oral cavity and restorations

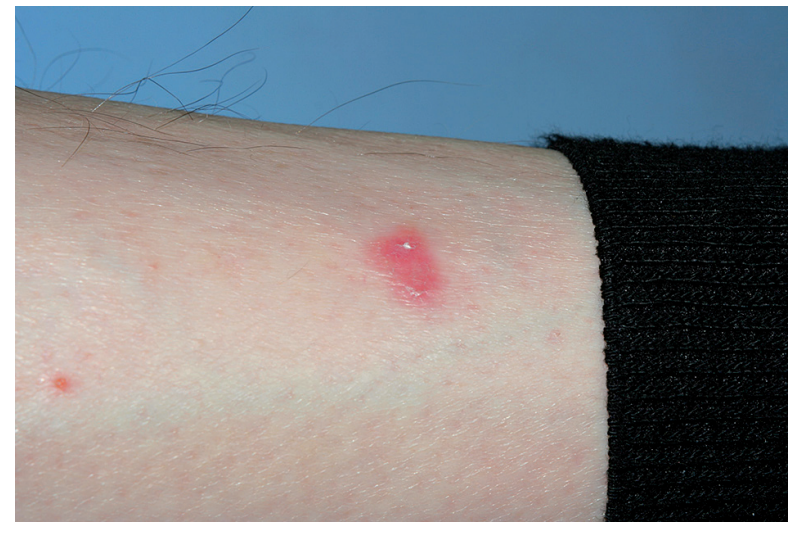

FIGURE 1. Lichen planus - follicular rash on the skin of shins

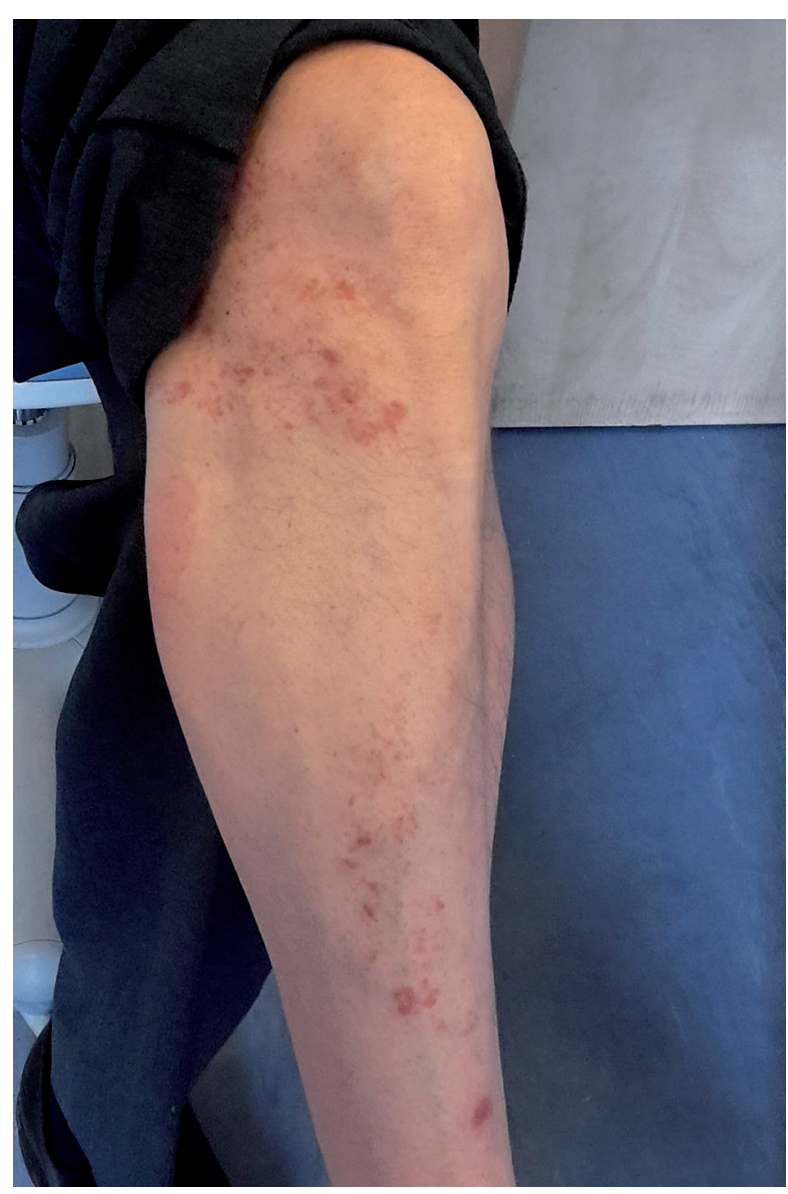

FIGURE 2. Lichen planus - follicular rash on the skin of shins

was evaluated as poor. A few cavities due to caries were visible, together with advanced pathological teeth abrasion and sharp tooth edges and fillings. No amalgam fillings were found.

A clinical examination of buccal mucosa showed the presence of white lines and striae mingling in irregular tree and ring shapes (Figures 3 and 4) and desquamative gingivitis in the area of incisors in the mandible 


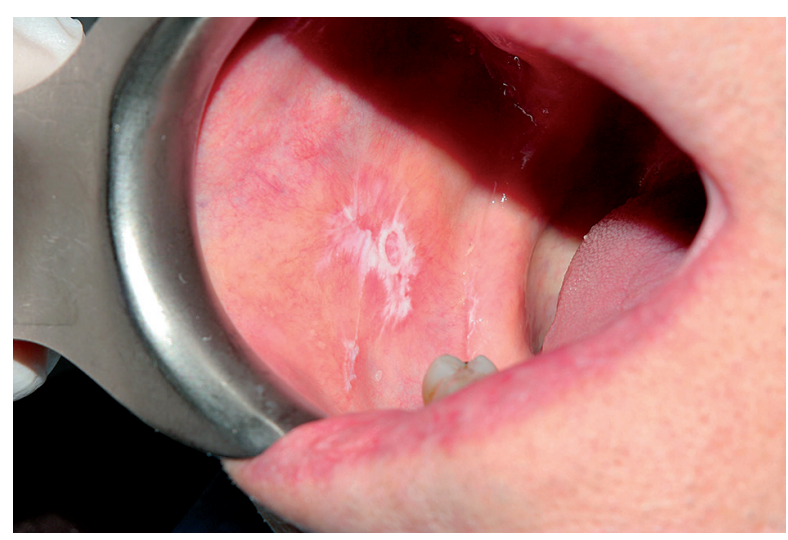

FIGURE 3. Lichen planus - reticular form on the buccal mucosa

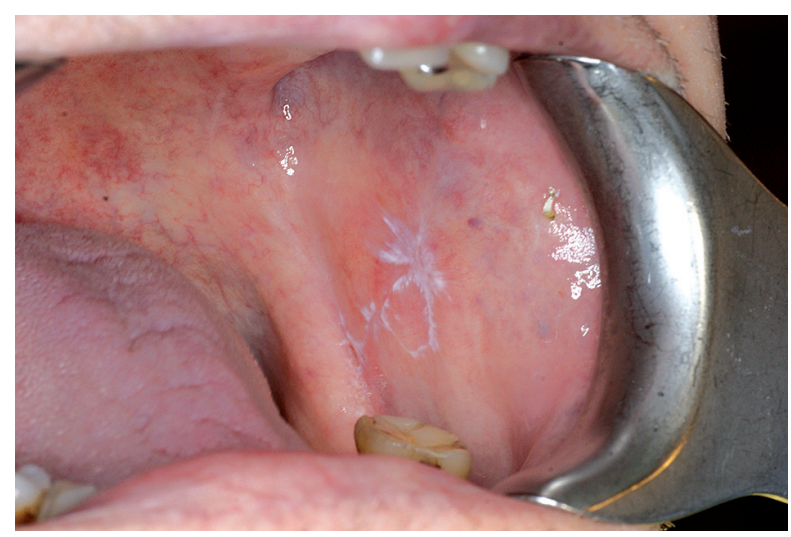

FIGURE 4. Lichen planus - reticular form on the buccal mucosa

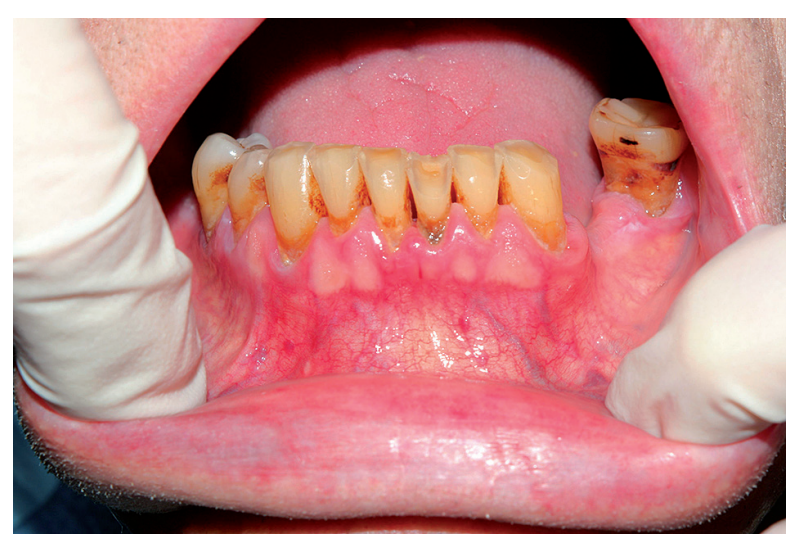

FIGURE 5. Lichen planus - desquamative gingivitis

(Figure 5). Mucosa surrounding the lesions did not show any visible pathological features.

Advanced horizontal alveolar ridge atrophy of the maxilla and the alveolar part of the mandible was found radiologically. Teeth 11 and 21, 36 - status after endodontic treatment, with a shadow of contrast material for radiological apexes.

On the basis of clinical examination, the initial diagnosis was formulated, being a reticular (simple) form of OLP. Supplementing the physical examination with data obtained from the patient's medical history, stating coexistence of diabetes and hypertension, as well as systemic hypotension and hypoglycaemic treatment, the initial diagnosis of Grinspan's syndrome was put forward.

Due to the likelihood of a possibility of the Koebner response occurrence, topical treatment started with the elimination of irritating agents. To this end, sharp edges of teeth and composite fillings were smoothened, scaling with polishing was performed, together with providing instructions on how to take care of the hygiene of the oral cavity and prosthetic restorations. Due to the presence of caries, the patient was referred for conservative treatment.

On the basis of subjective complaints found in the medical history, being the feeling of irritation and dryness in the oral cavity, a smear from the oral mucosa was ordered to make a microbiological test, together with determining sensitiveness to drugs.

Topical treatment of oral mucosa, covering the time of supplying results of additional tests, included using neutralising mouthwash ( $4 \%$ sol. aq. Natrium bicarbonicum, 3 times a day) diluted in the proportion: 1 spoon in one glass of water. After 14 days, the test result was received, in which abundant growth of a Candida kefyr colony was identified, sensitive to miconazole, nystatin and itraconazole. It was recommended to continue using the neutralising mouthwash (3 times a day) and antifungal treatment was implemented due to the sensitivity of the strain to the drugs. To this end, local application of gel with miconazole (Daktarin oral) was prescribed 3 times a day. The patient received dietary recommendations, including reduction of monosaccharide consumption, elimination of hot and sour meals, as well as avoidance of hot spices.

A follow-up visit was appointed after 14 days. The sense of dryness and irritation decreased significantly. The condition of mucous membrane and skin lesions remained unchanged. Local treatment was continued for 6 weeks. Two weeks after finishing the antifungal treatment, the therapeutic effectiveness evaluation was performed by making a check-up smear.

After 10 weeks from initiating the local treatment, the patient provided the smear result with a negative culture result for yeast-like fungi. He reported disappearance of irritation and dryness in the oral cavity. In clinical examination, continuous persistence of white lesions on the oral mucosa was identified and brownish papules on the left shin skin. Due to the nature of the lesions, i.e. a reticular form, lack of erosions and the lesions location, no direct indication for histopathological verification was identified at this stage of treatment. The patient did not consent to biopsy because of his old age and lack of severe pain. Maintenance therapy included using neutralising mouthwash alternatively with herbal wash with a protective and anti-inflammatory 
effect (linseed, mallow flower, chamomile and marshmallow). The patient awaits further follow-up. He comes regularly every 3 months. Lesions in the oral cavity and on the skin persist. Periods of exacerbation do not occur. He waits for new prosthetic restorations.

\section{CASE 2}

A 57-year-old patient, R.R., visited a doctor due to white lesions on the buccal mucosa. The lesions had been seen by a dentist about 4 weeks before, during a routine check-up examination. The lesions were accompanied with the feeling of dryness and irritation of the oral cavity.

It stemmed from the medical history that the patient had been treated by a cardiologist since 2005, due to diagnosed hypertension (treated with Co-Amlessa $8 \mathrm{mg} / 10 \mathrm{mg} / 2.5 \mathrm{mg}: 1-0-0)$ and was also regularly treated by a diabetologist for type 2 diabetes diagnosed in 2005 (Clucophage 750 mg: 1-0-0, NovoRapid Penfill 100 j./ml: 1-0-0, Insulatard Penfill - before a meal). Since 2006, he has also been treated for dyslipidemia (Ridlip $20 \mathrm{mg}$ : 1-0-0). The patient is on a low-fat diet based on a low glycemic index. He used to smoke cigarettes, but ceased about 3 years ago.

Extraoral clinical examination was without any tangible pathology.

In an intraoral examination, anodontia in the maxilla and interdental gaps and posterior teeth loss in the mandible were identified. According to the Galasińska-Landsbergerowa classification it is class $\mathrm{V}$ in the maxilla, and class IV in the mandible. According to the Eichner classification, losses were identified as $\mathrm{C} 2$. The patient had used a total acrylic prosthesis in the maxilla and a partial acrylic prosthesis in the mandible for about 3 years. The analysis of prostheses showed close fitting and adhesion to the prosthetic base.

The clinical examination was supplemented with radiological diagnostics. Based on an orthopantomographic image, advanced bone atrophy in the maxilla and the mandible was identified. Tooth 34 - condition after endodontic treatment with a shadow of contrast material to the radiological apex.

In the physical examination of the buccal mucosa, numerous symmetric milky-white streaks with treeshaped outlines were found, the image of which resembled a reticular form of Wilson's LP (Figures 6 and 7). At the same time, in the area of the toothless alveolar part of the mandible, in the molar and retromolar region, in the immediate proximity of buccal lesions, extensive uniform fields of opacity were visible with an opalescent surface, the clinical image of which suggested leukoplakia (Figure 8). In the remaining parts of the oral cavity no pathological lesions were observed. After the anamnesis, physical examination and thorough analysis of the course of general diseases and the systemic pharmacological treatment performed, initially, Grinspan's

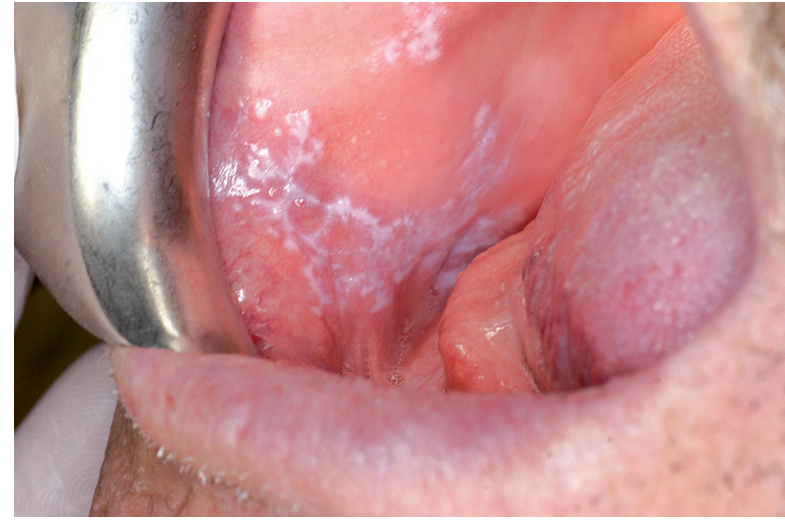

FIGURE 6. Lichen planus - reticular form on the buccal mucosa

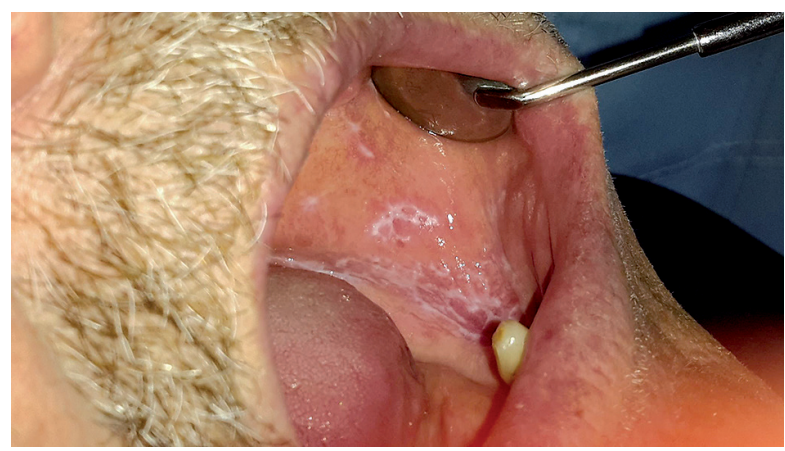

FIGURE 7. Lichen planus - reticular form on the buccal mucosa

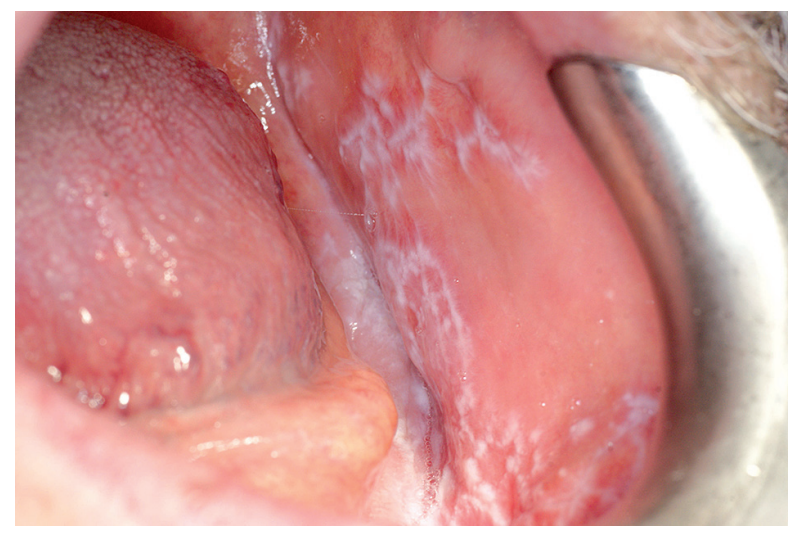

FIGURE 8. Leukoplakia of the toothless alveolar part of the mandible in the molar and retromolar region

syndrome was diagnosed within the scope of lesions on the buccal mucosa with a triad of symptoms: LP, hypertension and diabetes. Taking into account a long-term tobacco smoking addiction, a characteristic image and location of uniform opacities on the cornified gingiva, the initial diagnosis was as follows: homogeneous leukoplakia of the molar and retromolar region of the toothless alveolar part of the mandible.

The local treatment of lesions on the alveolar gingiva and buccal mucosa was applied by means of an aque- 
ous solution of vitamin $\mathrm{A}+\mathrm{D}_{3}$ (3 times a day) and neutralising mouthwash ( $4 \%$ sol. aq. Natrium bicarbinicum). A smear was ordered for a microbiological test of the oral mucosa. The patient was also instructed on hygiene, taking into account prosthetic restorations. The information was provided about indications for histopathological verification of the clinical diagnosis of leukoplakia. A follow-up visit took place 3 weeks after conducting local treatment. The patient had a negative result of the microbiological culture.

Clinically, slight reduction of white lesions on the alveolar part of the mandible was reported. The condition of the buccal mucosa did not improve noticeably. Continuation of swabbing of lesions on the alveolar part of the mandible with an aqueous solution of vitamin $\mathrm{A}+\mathrm{D}_{3}$ was recommended. Gel with tannin (Salumin) was prescribed to swab the buccal mucosa 3 times a day. The next visit was appointed after 2 months. Lesions on the alveolar gingiva disappeared completely, but the lesions on the buccal mucosa with a characteristic treeshaped clinical image, corresponding to LP (a reticular form), persisted. Due to extensive lesions, it was clinically impossible to exclude unambiguously the co-existence of LP lesions with leukoplakia-type lesions, so a fully conscious decision was made, with the patient's consent, to verify it histopathologically. In local anaesthesia with a $4 \%$ solution of Articaine hydrochloride + epinephrine (Ubistesin forte), a sample tissue was collected with a margin of healthy tissue, and the wound was sewn with non-absorbable, synthetic sutures (Prolene 5.0). The collected material was sent to a histopathological laboratory. Sutures were removed after 7 days. Microscopic evaluation of the collected bioptate indicated the presence of hyper- and parakeratosis, degeneration of keratinocytes and inflammatory infiltration, together with confirmation of the initial clinical diagnosis of LP. Local protective treatment of lesions on the buccal mucosa (Salumin and neutralising mouthwash) was continued. The patient attended follow-up visits every 3 months. Although systemic drugs remained unchanged, preservation of good hygiene of the oral cavity and prosthetic restorations, as well as local protective treatment, had an impact on considerable reduction of lesions in the oral cavity. The patient was told to make an urgent appointment if lesions in the oral cavity worsened or if the disease evolved.

\section{DISCUSSION}

The occurrence of intraoral lesions of the LP in patients with hypertension and diabetes was described for the first time by Grinspan et al. in 1963, and subsequently called Grinspan's syndrome. Some authors question the existence of this disease, linking more frequent occurrence of LP lesions in patients with hypertension or diabetes with the drugs they take [40]. Data from literature show that a considerable number of drugs taken during systemic diseases may contribute to intraoral lesions, which clinically may conform with the image of LP [26-32, 40]. It enabled separation of OLL, which might be a disease in themselves, and those which might result from exacerbation of OLP in response to the drugs taken. The study of Habbab et al. showed the occurrence of lichenoid lesions in $3.6 \%$ of patients taking drugs for cardiovascular disorders [41]. It is not always possible to change medication. In justified cases, it may be done in consultation with the practitioner.

In a differential diagnosis of the reticular form of LP, one needs to take into consideration also such lesions as naevus spongiosus albus, lesions relating to a chronic habit of biting or retracting the oral mucosa, lesions in lupus erythematosus, candidosis or GVHD. On the other hand, manifestation of oral diseases with an autoimmunological background, such as pemphigus, pemphigoid or lupus erythematosus, can be erroneously diagnosed as an erosive or atrophic form of LP $[1,5,14,27]$.

Patients with a diagnosed Grinspan's syndrome should be treated regularly by a diabetologist, cardiologist and dermatologist (in the case of manifested skin lesions). Regular visits to the Oral Mucosal Diseases Clinic every 3 months should supplement interdisciplinary cooperation, due to a risk of transformation of simple LP lesions into complicated forms, frequently induced by stress, dietary negligence, mechanical irritation, drug changes or exacerbation of general diseases. Special attention is required in the case of patients suffering from the erosive form of LP, which has been referred to by the $\mathrm{WHO}$ as a precancerous condition $[35,44]$. A possible complication on the basis of the erosive form of LP is the development of oropharyngeal squamous cell carcinoma (OSCC). The risk of malignancy ranges from 0.4 to $5.3 \%[19,43,44]$. According to Knychalska-Karwan, in patients with lichen the risk of malignant transformation is 10-20 times higher than in the average population [3]. Dynamic lesions and those resistant to the local treatment require histopathological verification, according to the so-called golden 2-week principle [45].

Simple forms of LP are often without any symptoms and they do not require any pharmacological intervention. An important aspect of treating OLP is informing the patient properly about the chronic nature of this disease. Although typical cases of skin LP are often subject to remission, oral lichen withdraws only in some patients [19]. The basis for implementing treatment of the lesions should be determined based on thorough anamnesis and physical examination and, if possible, confirmed with a histopathological test [32, 37, 45]. Local irritating agents, with special emphasis on dental deposits (tartar), sharp edges of fillings and prosthetic restorations should be eliminated. An important aspect is to modify the diet, excluding hot, salty, spicy and hard food $[26,31]$. Information from the medical history with regard to subjective symptoms in the form of irritation and dryness of the oral cavity is indicative of per- 
forming microbiological tests, since data from the literature indicate a high percentage (30-50\%) of fungal infection overlapping with lesions due to LP $[5,46]$. In the case of a reticular form of OLP, protective treatment by means of herbal infusions (linseed, marshmallow and mallow flower) is recommended, together with regular visits every 2-3 months [31, 47, 48]. In more complex forms of OLP (including bullous and erosive forms), positive effects are achieved as a result of local treatment with $0.1 \%$ tacrolimus. In the local treatment of keratotic lesions it seems appropriate to implement retinoids, due to their capability of regulating keratotic and keratinocyte differentiation processes, facilitating exfoliation of dead cells, reducing inflammation and stimulating collagen and angiogenesis synthesis. In advanced forms, local administration of steroids is sometimes necessary $[26,31,46,49,50]$.

\section{CONCLUSIONS}

In both cases presented above, a triad of symptoms characteristic for Grinspan's syndrome was identified. In the first case, confirmation of the syndrome was based only on clinical diagnosis of oral LP and data from medical history confirming the skin form of LP, whereas in the second description, the clinical diagnosis was additionally confirmed histologically. Regardless of the kind of intraoral lesions, the practitioner should be oncologically vigilant. Long-term observations are necessary to monitor lesions and potential malignant transformations.

\section{CONFLICT OF INTEREST}

The authors declare no potential conflicts of interest with respect to the research, authorship, and/or publication of this article.

\section{References}

1. Lozada-Nur F, Miranda C. Oral lichen planus: epidemiology, clinical characteristics and associated diseases. Semin Cutan Med Surg 1997; 16: 273-277.

2. Bernard NA, Scully C, Eveson JW, et al. Oral cancer development in patients with oral lichen planus. J Pathol Med 1993; 22: 421-424.

3. Kurnatowska AJ, Stankiewicz A. Pęcherzowa postać liszaja płaskiego - opis przypadku. Dent Med Probl 2004; 41: 779-782.

4. Scully C, El-Com M. Lichen planus: review and update on pathogenosis. J Oral Pathol 1985; 14: 431-458.

5. Radwan-Oczko M, Mendak M. Różnicowanie leukoplakii błony śluzowej jamy ustnej i ustnej postaci liszaja płaskiego na podstawie piśmiennictwa i własnych obserwacji. J Stoma 2011; 64: 355-370.

6. Zegarelli DJ, Sabbagh E. Relative incidence of intraoral pemphegus vulgaris, mucus membrane pemphegoid and lichen planus. Ann Dent 1989; 48: 5-7.

7. Axell T, Rundquist L. Oral lichen planus: a demographic study. Community Dent Oral Epidemiol 1987; 15: 52-56.

8. Eversole LR. Immunopathogenesis of oral lichen planus and recurrent aphthous stomatitis. Semin Cutan Med Surg 1997; 16 284-294.
9. Kozak I, Ziarkiewicz-Wróblewska B, Grzegorczyk-Jaźwińska A, et al. Ocena obrazu histologicznego i analiza immunohistochemiczna składu nacieku w chorobie przeszczep przeciw gospodarzowi i w liszaju płaskim. Dent Med Probl 2010; 47: 314-321.

10. Charazińska-Carewicz K, Grabowska E, Górska R, Król M. Ocena liczebności subpopulacji limfocytów krwi obwodowej u chorych z liszajem płaskim. J Stoma 2004; 57: 162-168.

11. Campisi G, Fede D, Craxi A, et al. Oral lichen planus, hepatitis $\mathrm{C}$ virus, and HIV: no association in a cohort study from an area of high hepatitis C virus endemicity. J Am Acad Dermatol 2004; 51: 364-370.

12. Ivanowski K, Nakowa M, Warburton G, et al. Psychological profile in oral lichen planus. J Clin Periodontol 2005; 32: 1034-1040.

13. Mahboobi N, Agha-Hosseini F, Lankerani KB. Hepatitis $C$ virus and lichen planus: the real association. Hepat Mon 2010; 10: 161-164.

14. Mollaoglu N. Oral lichen planus: a review. Br J Oral Maxillofac Surg 2000; 38: 370-377.

15. Sopper DE, Patterson JW, Hurt GW, et al. Lichen planus of the vulva. Obstet Gynecol 1988; 127: 1684-1688.

16. Mckay M. Vaginitis and vulvovaginitis: cutaneous considerations. Am J Obstet Gynecol 1991; 165: 1176-1182.

17. Bhattacharya M, Kaur I, Kumar B. Lichen planus: a clinical and epidemiological study. J Dermatol 2000; 27: 576-582.

18. Scully C, Carrozzo M. Oral mucosal desease: Lichen planus. Br J Oral Maxillofac Surg 2008; 46: 15-21.

19. Munde A, Karle RR, Wankhede PK, et al. Demographic and clinical profile of oral lichen planus: a retrospective study. Contemp Clin Dent 2013; 4: 181-184.

20. Eisen D, Carrozzo M, Bagan-Sebastian JV, Thongprasom K. Oral lichen planus: clinical features and management. Oral Dis 2005; 11: 338-349.

21. Charazińska-Carewicz K, Ganowicz E, Górska R, Król M. Porównanie odporności komórkowej i humoralnej u chorych z postacią siateczkową i nadżerkową liszaja płaskiego w jamie ustnej. Dent Med Probl 2004; 41: 711-716.

22. Bagan-Sebastian JV, Milian-Masanet MA, Penarrocha-Diago M, Jimenez Y. A clinical study of 205 patients with oral lichen planus. J Oral Maxillofac Surg 1992; 50: 116-118.

23. Slavounou A, Laskaris G. Frequency of desquamative gingivitis in skin diseases. Oral Surg Oral Med Oral Pathol 1983; 56: 141-144.

24. Krasowska D. Liszaj płaski. Nowa Med 2000; 7: 21-24.

25. Wiess G, Shemer A, Trau H. The Koebner phenomenon: review of the literature. J Eur Acad Dermatol Venerol 2002; 16: 241-248.

26. Serrano-Sanchez P, Bagan JV, Jimenez-Soriano Y, Sarrion G. Drug induced oral lichenoid reactions. A literature review. J Clin Exp Dent 2010; 2: 71-75.

27. Knychalska-Karwan Z, Nowak T. Przyczynek do diagnostyki zmian liszajowych w jamie ustnej. Por Stoma 2009; 7-8: 273-277.

28. Ganowicz E, Kozak I, Ziarkiewicz-Wróblewska B, et al. Obraz histopatologiczny $\mathrm{i}$ immunohistochemiczny w liszaju płaskim in situ w zależności od przebiegu choroby. Dent Med Probl 2008; 45: 248-254.

29. Bandal V, Ashwinirani SR, Nayak A, et al. Analysis of association of systemic drugs in oral lichen planus lesions. Am J Drug Del Therap 2015; 2: 44-52.

30. Habbab KM, Moles DR, Porter SR. Potential oral manifestations of cardiovascular drugs. Oral Diseases 2010; 16: 769-773.

31. Ismail SB, Kumar SK, Zain RB. Oral lichen planus and lichenoid reactions: etiopathogenesis, diagnosis, management and malignant transformation. J Oral Sci 2007; 35: 412-416.

32. Lamey PJ, Gibson J, Barclay SC, Miller S. Grinspan's syndrome: a drug-induced phenomenon? Oral Surg Oral Med Oral Pathol 1990; 70: 184-185.

33. Karatsaidis A, Schreurs O, Helgeland K, et al. Erythematous and reticular forms of oral lichen planus and oral lichenoid reactions differ in pathological features related to disease activity. J Oral Pathol Med 2003; 32: 275-281.

34. Jose M, Raghu AR, Rao NN. Evaluation of mast cells in oral lichen planus and oral lichenoid reaction. Indian J Dent Res 2001; 12: 175-179. 
35. Juneja M, Mahajan S, Rao NN, et al. Histochemical analysis of pathological alterations in oral lichen planus and oral lichenoid lesions. J Oral Sci 2006; 48: 185-193.

36. Watanabe C, Hayashi T, Kawada A. Immunofluorescence study of drug-induced lichen planus-like lesions. J Dermatol 1981; 8: 473-477.

37. Colella G, Itro A, Corvo G. A case of a carcinoma arising in lichen planus in a subject with diabetes mellitus and arterial hypertension (Grinspan's syndrome). Minerva Stomatol 1992; 42: 417-420.

38. Salem CB, Chenguel L, Ghariani N, et al. Captopril-induced lichen planus pemphigoides. Pharmacoepidemiol Drug Saf 2008; 17: 722-724.

39. Aldelaimi TN. Occurence of lichen planus in diabetes mellitus J Bagh Coll Dentistry 2005; 17: 62-65.

40. Rao GS, Pai GS, Gatha SR, Ganesh SP. Cutaneous manifestations of diabetes mellitus. Indian J Dermatol Venerol Leprol 1997; 63: 232-234.

41. Habbab KM, Moles DR, Porter SR. Potential oral manifestations of cardiovascular drugs. Oral Dis 2010; 16: 769-773.

42. Rad M, Hashemipoor MA, Mojtahedi A, et al. Correlation between clinical and histopathologic diagnoses of oral lichen planus based on modified WHO diagnostic criteria. Oral Surg Oral Med Oral Pathol Oral Radiol Endod 2009; 107: 796-800.

43. Eisen D. The evaluation of cutaneous, genital, sculp, nail, esophageal and ocular involvement in patients with oral lichen planus. Oral Surg Oral Med Oral Pathol Oral Radiol Endod 1999; 88: 431-436.

44. Shi P, Liu Z, He Q, Jiang W. Podoplanin and ABCG2: malignant transformation risk markers for oral lichen planus. Cancer Epidemiol Biomarkers Prev 2010; 19: 844-849.

45. Peterson L, Ellis E, Hupp J, Tucker M. Chirurgia stomatologiczna i szczękowo-twarzowa. Czelej, Lublin 2001.

46. Radwan-Oczko M. Topical application of drugs used in treatment of oral lichen planus lesions. Adv Clin Exp Med 2013; 22: 893-898

47. Mignogna MD, Lo Muzio L, Lo Russo L, et al. Clinical guidelines in early detection of oral squamous cell carcinoma arising in ora lichen planus: a 5-year experience. Oral Oncol 2001; 37: 262-267.

48. Mignogna MD, Fedele S, Lo Russo L. Dysplasia/neoplasia surveillance in oral lichen planus patients: a description of clinical criteria adopted at a single centre and their impact on prognosis. Ora Oncol 2006; 42: 819-824.

49. Bronikowska A, Wojnowska D. Zastosowanie retinoidów w dermatologii. Nowa Medycyna 1/2003.

50. Al Hashimi I, Schifter M, Lockhart PB, et al. Oral lichen planus and oral lichenoid lesions: diagnostic and therapeutic considerations. Oral Surg Oral Med Oral Pathol Oral Radiol Endod 2007; 103: $1-12$. 